\title{
Characterisation and Corrosion Resistance of TiCrN Composite Coating on Steel by Physical Vapour Deposition Method
}

\author{
Vijayasarathi Prabakaran ${ }^{1} \cdot$ Kavitha Chandrasekaran ${ }^{2}$
}

Received: 22 June 2016/Revised: 11 August 2016/Accepted: 23 August 2016/Published online: 29 August 2016

(c) Springer International Publishing Switzerland 2016

\begin{abstract}
The present work aims at the development of an energy efficient and eco-friendly approach for the deposition of TiCrN composite coating. The study describes the deposition, characterisation and corrosion resistance of the composite coating. The methods of evaluation include assessment of colour and uniformity by physical and visual observations, adhesion by pull-off adhesion test, morphological features by optical and scanning electron microscopy, and chemical composition by energy-dispersive $\mathrm{X}$-ray analysis. The corrosion resistance of the coatings in $3.5 \% \mathrm{NaCl}$ was evaluated by potentiodynamic polarisation studies. The finding of this study reveals that the adhesion of the coating on uncoated steel and adhesion of paint film on $\mathrm{TiCrN}$ composite-coated steel were found to be good. A potentiodynamic polarisation result confirms that $\mathrm{TiCrN}$ composite coating offers a better corrosion resistance than uncoated steel.
\end{abstract}

Keywords TiCrN coatings - Corrosion resistance - SEMEDX $\cdot$ Surface morphology

\section{Introduction}

In recent years, different kinds of thin film deposition processes have been developed to enhance the tribological behaviour of the coatings in heavy duty components such

Vijayasarathi Prabakaran

vijayasarathiprabakaran@gmail.com

1 Department of Mechanical Engineering, Jeppiaar Institute of Technology, Chennai, Tamil Nadu, India

2 Department of Chemistry, Jeppiaar Institute of Technology, Chennai, Tamil Nadu, India as cutting tools and gears. The competence of composite coating in severe operational stipulation can be endorsed to the high hardness, wear resistance and corrosion resistance in high-speed machineries. This opens up a new avenue for the development of physical vapour deposition (PVD) in the field of composite coating. PVD describes a variety of vacuum deposition methods which can be used to produce thin films. PVD uses physical process (such as heating or sputtering) to produce a vapour of material, which is then deposited on the object which requires coating. PVD is used in the manufacture of items which require thin films for mechanical, optical, chemical or electronic functions. PVD technique (ion plating, sputtering and arc evaporation) provides a promising ground for the deposition of hard coatings by the formation of dense adhesive film at low deposition temperatures. Corrosion protection capability of PVD coatings is widely reported in Ref. [1]. In many applications, the coated parts are frequently exposed to an aggressive working environment, for instance, a chloride containing corrosive medium which has strong effects in promoting localised corrosion, particularly in marine environment [2]. Recent studies show that $80 \%$ of the total cost for the protection of metals is related to coating application [3]. Coatings provide a way of extending the limits of the use of the materials at the upper end of performance capabilities, by allowing the mechanical properties of the substrate materials to be maintained while protecting against wear, oxidation, and corrosion [4]. Transition metal nitride-based hard coatings (especially TiN) have been successfully used for the materials protection since the commercialisation of PVD TiN coatings in the early 1980s [5]. The use of the ternary system Ti$\mathrm{Al}-\mathrm{N}$ as a base for a new hard coating material is one of the most successful new trends in the titanium nitride technology [6]. TiAlN thin films are now commercially 
available as wear resistant coatings for high-speed machining, due to their high hardness, excellent oxidation and corrosion resistance. The presence of $\mathrm{Al}$ in TiAlN coatings overcomes the oxidation problems due to the presence of a superficial layer of $\mathrm{Al}_{2} \mathrm{O}_{3}$ formed at high temperatures [7-13]. In comparison with TiN-based coatings (e.g. TiAlN), CrAlN coatings have been reported exhibiting higher oxidation resistance, as both the chromium and aluminium could form protective oxides which suppressed oxygen diffusion [2]. Many recent reports have shown the improvement made on cutting and drilling lifetime versus speed performance, wear and friction reduction and corrosion resistance when these materials are used in the coating of the tools [6]. Based on this perspective, the present study aims to develop TiCrN composite coating to achieve superior oxidation resistant properties.

\section{Experiment Details}

Mild steel discs (dimensions: $40 \mathrm{~mm} \varnothing, 12 \mathrm{~mm}$ thick) were used as a substrate materials. Substrates were cleaned ultrasonically with acetone, ethanol and 2-propanol sequentially before subjected to PVD (sputtering) process. The colour and uniformity of the coatings deposited under varying experimental conditions were assessed by visual observation. The nanostructured thin $\mathrm{TiCrN}$ coating with a thickness around $4 \mu \mathrm{m}$ was deposited on the substrates. Optical microscopy (Leica DMLM metallurgical microscope with QWin Image analyzer) was used to assess the microstructure of these steels after PVD. The surface morphology of the TiCrN composite coating was assessed by field emission scanning electron microscopy (FE-SEM), while their chemical composition was ascertained by energy-dispersive X-ray analysis (EDX) attached with the FE-SEM (Carl Zeiss Supra 55 Cambridge, UK). The corrosion resistance of uncoated steels as well as those composite coated with $\mathrm{TiCrN}$, in $3.5 \% \mathrm{NaCl}$ was evaluated by potentiodynamic polarisation studies, using a potentiostat/galvanostat/frequency response analyzer of ACM Instruments (model Gill AC). The uncoated and TiCrN composite-coated steels formed the working electrode, while a saturated calomel electrode (SCE) and a graphite rod served as the reference and auxiliary electrodes, respectively. These three electrodes were placed within a flat cell (Friction and Wear Tech., Chennai, India) in such a way that only $1 \mathrm{~cm}^{2}$ of the working electrode was exposed to the $3.5 \% \mathrm{NaCl}$. Potentiodynamic polarisation measurements were carried out in the potential range from $-250 \mathrm{mV}$ versus $\mathrm{SCE}$ in the cathodic direction to $+250 \mathrm{mV}$ versus SCE in the anodic direction from OCP at a scan rate of $10 \mathrm{mV} / \mathrm{min}$. The corrosion potential $\left(E_{\text {corr }}\right)$ and corrosion current density $\left(i_{\text {corr }}\right)$ were determined using Tafel extrapolation method. The electrochemical studies were repeated at least three times to ensure reproducibility of the test results.

\section{Results and Discussion}

\subsection{Characteristics of the TiCrN Composite Coatings Deposited on Steel}

\subsubsection{Colour, Uniformity, Adherence and Porosity}

The TiCrN composite coatings are uniform and grey in colour. The optical micrographs of the uncoated substrate and thin TiCrN composite-coated substrate are depicted in Fig. 1.

\subsubsection{Adhesion Test}

Adherence of the coating on the steel substrate is in general good when evaluated by the pull-off adhesion test [14] using a pressure-sensitive adhesive tape. The photographic
Fig. 1 Optical micrographs $(\times 200)$ of the surface of uncoated substrate (a) and TiCrN composite-coated surface (b)
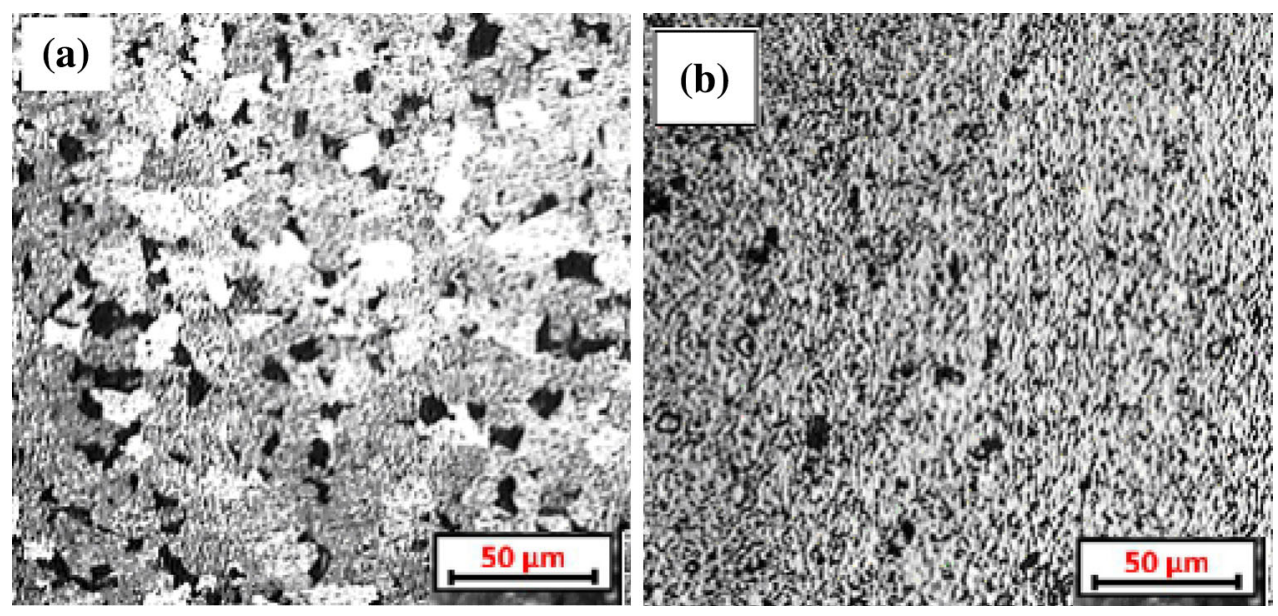


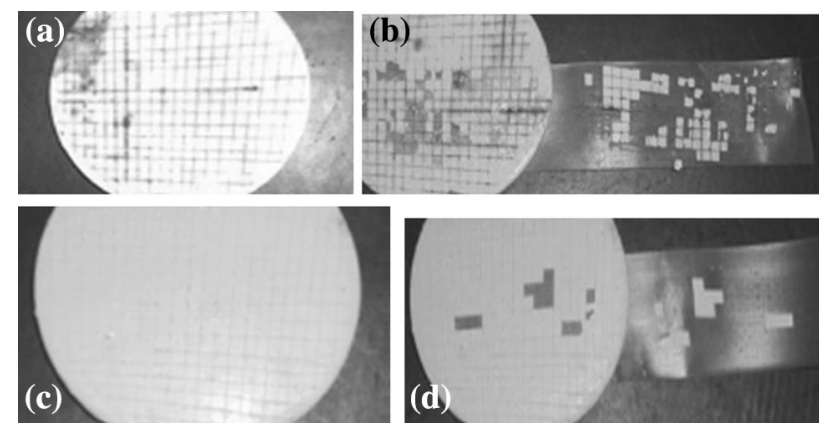

Fig. 2 Photographic images of TiCrN composite-coated and painted steel after immersion in deionized water at $45{ }^{\circ} \mathrm{C}$ for $240 \mathrm{~h}(\mathbf{a}, \mathbf{c})$ and after adhesion testing (b, d): (a, b) uncoated steel, (c, d) $\mathrm{TiCrN}$ composite-coated steel prepared by PVD method

images of painted uncoated steel and $\mathrm{TiCrN}$ composite coated followed by painted steel after immersion in deionised water at $45{ }^{\circ} \mathrm{C}$ for $240 \mathrm{~h}$ and after adhesion testing are shown in Fig. 2. It is evident from Fig. 2 that uncoated steel exhibits red rust formation on the scribed areas (Fig. 2a) and the paint film is removed from at least $40-50 \%$ of the area when tested with an adhesive tape (Fig. 2a). The TiCrN composite-coated steel prepared by the PVD method exhibits the formation of red rust in some areas of the scribed region (Fig. 2b), and the paint film is removed only in about $10-20 \%$ of the area when tested with an adhesive tape (Fig. 2b). The presence of a thin layer of titanium oxide and chromium oxide over the steel prevents direct contact of the steel with the deionized water.

The ferroxyl test performed on coated steel shows no sign of Prussian blue colour spots (formed due to the reaction between the ferrous ions in the uncoated areas and ferricyanide present in the test solution) over the entire area. This confirms the formation that the entire surface of the steel sample is covered by a thin layer of $\mathrm{TiN}$ and $\mathrm{CrN}$ coatings that are deposited together. The results of the ferroxyl tests reveals that coatings prepared by this PVD methodology could probably be considered pore free.

\subsubsection{Progressive Load Scratch Test}

Scratch tests were performed using a Reveres scratch tester which has a load range of 1-300 N. Figure 3 shows the plot graph view of progressive load scratch testing (PLST). It is observed that the coefficient of friction slightly increases with load and saturates at a value around 0.1 , in the applied load range.

A mixture of the deformation mechanisms was found to be operated during PLST due to the imposed loading conditions. Three different regimes of coating deformation were identified, on the basis of the acoustic emission signal and the variation in the friction coefficient. The corresponding optical images and SEM micrographs of the three different regimes are depicted in Fig. 4, respectively. Based on the acoustic emissions in the PLST of the TiCrN coated steel, the average adhesive strength is believed to be around $12 \mathrm{~N}$.

\subsubsection{Surface Morphology}

The surface morphology of $\mathrm{TiCrN}$ composite coatings deposited on steel by PVD method and its cross-sectional morphology are shown in Fig. 5. It is observed from the
Fig. 3 Plot of the friction coefficient and acoustic emission signal versus normal load

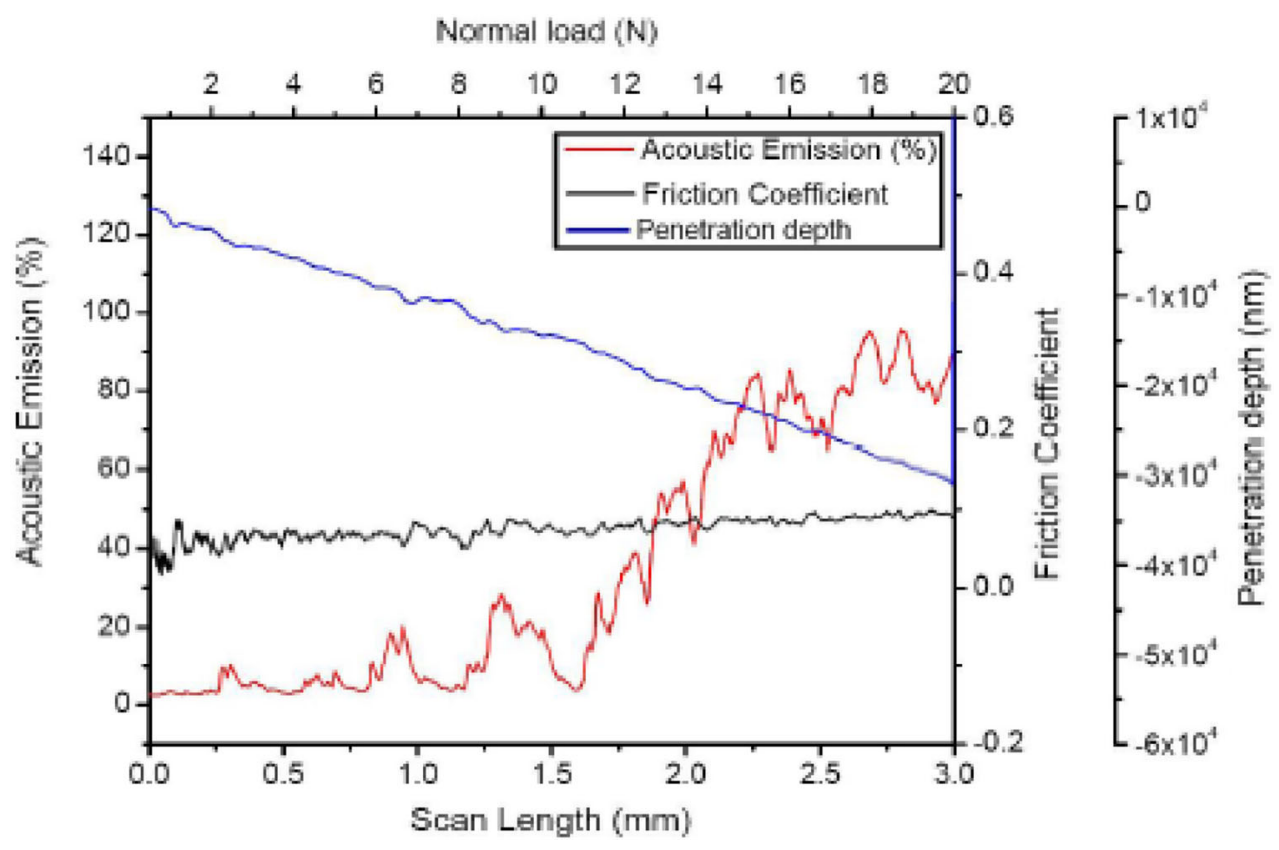


Fig. 4 Optical images revealing the surface damage during PLST at a $0-7 \mathrm{~N}$, b 7-12 $\mathrm{N}$ and c $12-18 \mathrm{~N}(\times 150$ magnification)
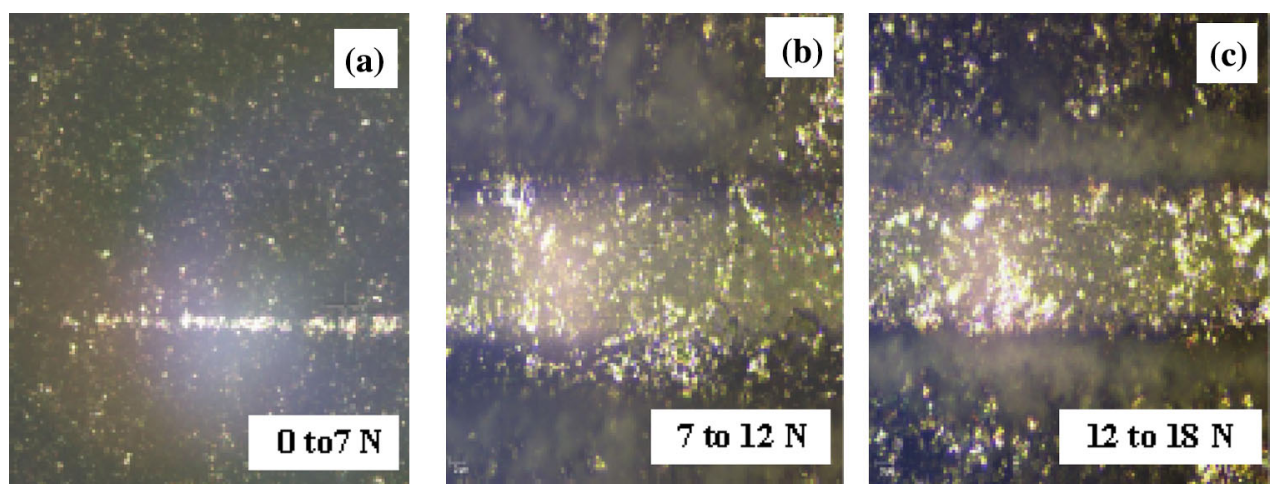
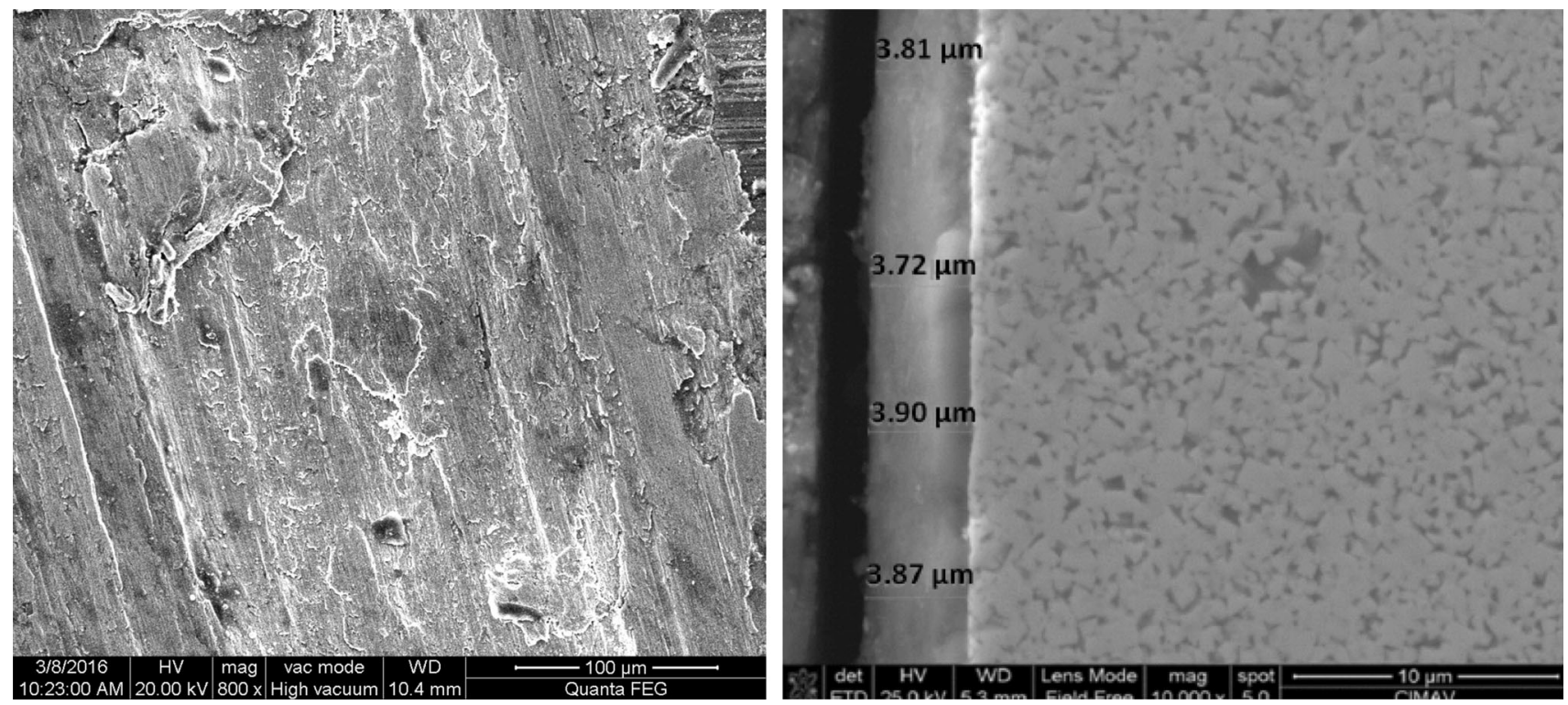

Fig. 5 Surface morphology (a) and cross section (b) of TiCrN composite coating deposited by PVD method

surface morphology (Fig. 5a) that the resultant coating is homogeneously deposited all over the substrate. The crosssectional morphology of the $\mathrm{TiCrN}$ composite coating deposited on steel (Fig. 5b) by PVD method indicates that the coating is homogeneous and with the thickness of the coating in the range of $3.72-3.90 \mu \mathrm{m}$. The EDX of uncoated and TiCrN composite-coated steel substrates is shown in Fig. 6. EDX results reveal that the alloying elements in uncoated steel substrate (Fig. 6a) is completely hidden by the TiCrN composite coating (Fig. 6b).

\subsubsection{Corrosion Behaviour of TiCrN Composite Coating Deposited by PVD Method}

The potentiodynamic polarisation curves of uncoated and transition metal nitride composite-coated steel ( $\mathrm{TiCrN})$ in $3.5 \% \mathrm{NaCl}$ solution is shown in Fig. 7. The corrosion potential $\left(E_{\text {corr }}\right)$, corrosion current density $\left(i_{\text {corr }}\right)$ and corrosion rate of uncoated and $\mathrm{TiCrN}$ composite-coated steel in $3.5 \% \mathrm{NaCl}$ solution are depicted in Table 1 . The corrosion current density and the corrosion potential were obtained by the intersection of the extrapolation of anodic and cathodic Tafel curves. The corrosion potential and corrosion current densities of the TiCrN composite coating render anodic shift in $E_{\text {corr }}$ with a corresponding decrease in $i_{\text {corr }}$ which is lower than that of the uncoated steel. It is evident that compared to the uncoated steel, TiCrN composite-coated steels offers a better corrosion resistance. The observed variation in the $E_{\text {corr }}$ and $i_{\text {corr }}$ of the coatings deposited by $\mathrm{TiCrN}$ is due to the volume fraction of $\mathrm{Ti}$ and $\mathrm{Cr}$ in the resultant composite coating. The anodic shift in $E_{\text {corr }}$ with a corresponding decrease in $i_{\text {corr }}$ is due to the build-up of chromium corrosion products on the surface of the coated steel, which acts as a barrier layer, thus preventing the corrosion attack of steel.

Since the potentiodynamic polarisation result confirms that composite coating deposited by PVD method provides ample avenues to manipulate the volume fraction of 

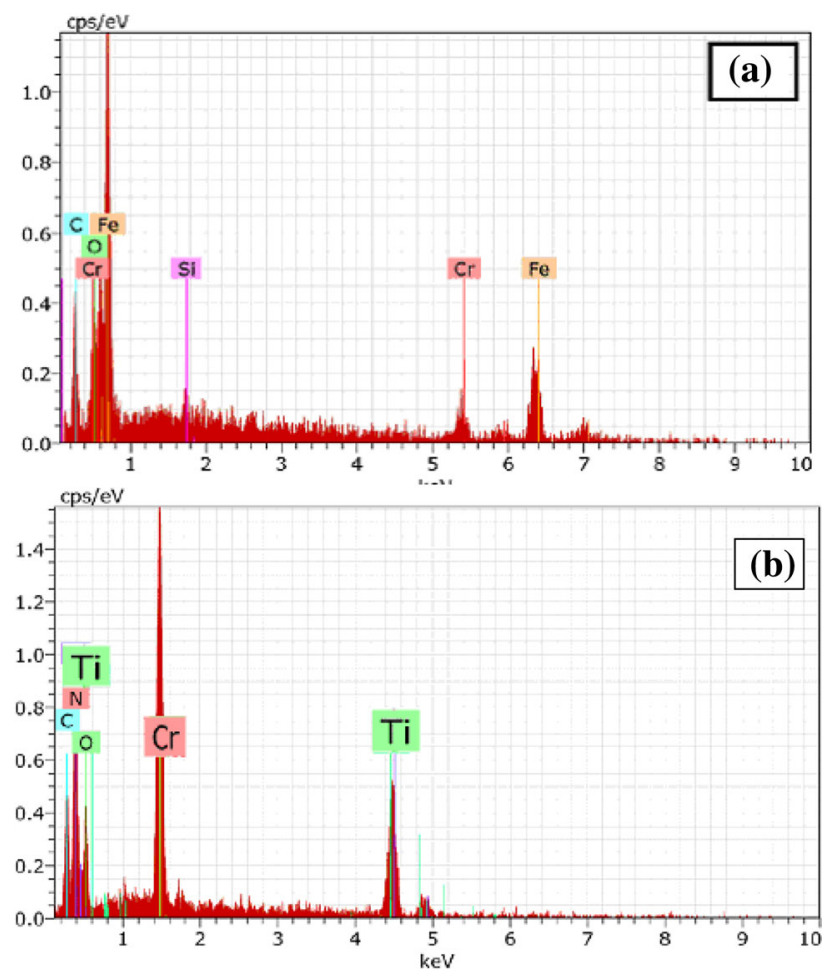

Fig. 6 EDX of uncoated steel substrate (a) and TiCrN composite coating (b) deposited by PVD method

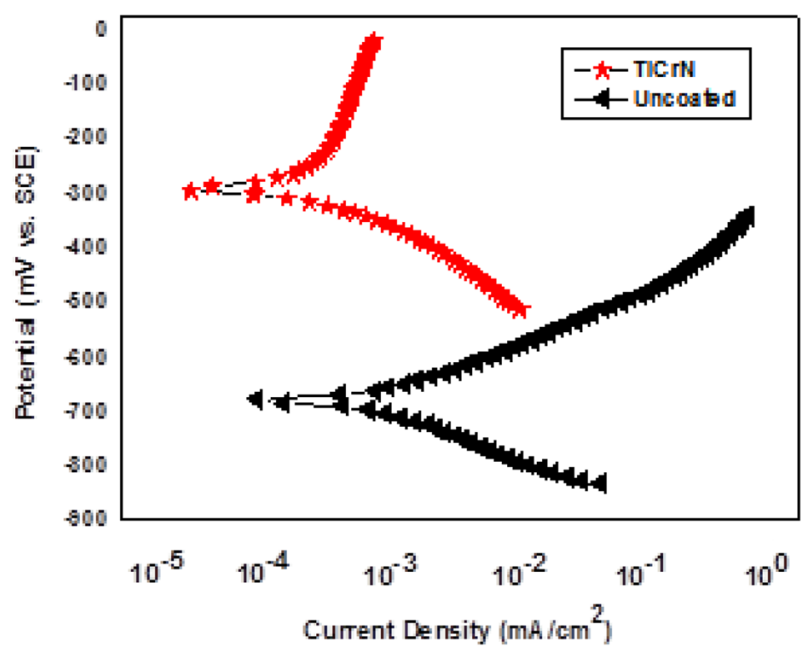

Fig. 7 Potentiodynamic polarisation curves of uncoated and $\mathrm{TiCrN}$ composite-coated steel in $3.5 \% \mathrm{NaCl}$ solution

Table 1 Corrosion potential $\left(E_{\text {corr }}\right)$, corrosion current density $\left(i_{\text {corr }}\right)$ and corrosion rate of uncoated and TiCrN composite-coated steel in $3.5 \% \mathrm{NaCl}$ solution

\begin{tabular}{lllll}
\hline $\begin{array}{l}\text { S. } \\
\text { No. }\end{array}$ & $\begin{array}{l}\text { Sample } \\
\text { specification }\end{array}$ & $\begin{array}{l}E_{\text {corr }}(\mathrm{mV} \text { vs } \\
\text { SCE })\end{array}$ & $\begin{array}{l}i_{\text {corr }}(\mathrm{mA} / \\
\left.\mathrm{cm}^{2}\right)\end{array}$ & $\begin{array}{l}\text { Corrosion rate } \\
(\text { mils/year })\end{array}$ \\
\hline 1. & Uncoated & -692.07 & 0.001935 & 1.7956 \\
2. & TiCrN & -295.92 & 0.001033 & 0.4717 \\
\hline
\end{tabular}

elements in the composite coating by a careful choice of materials with varying degrees of corrosion protection.

\section{Conclusion}

The findings of the study reveal that PVD method could be utilised as an energy efficient and eco-friendly method to deposit TiCrN composite coatings on steel. The amount of composite coating deposited on steel is increased with an increase in treatment time. The surface appearance of $\mathrm{TiCrN}$ composite coating is light grey in colour. The optical micrographs and surface morphological features reveal that the coating is uniform and in microstructure. EDX results also further confirm the presence of $\mathrm{Ti}, \mathrm{Cr}$ and $\mathrm{N}$ in the composite coating. Adherence of the $\mathrm{TiCrN}$ composite coating on the steel substrate as well as the paint coating applied on top of the composite coating is good when evaluated by the pull-off adhesion test using an adhesive tape. Wet adhesion measurement reveals that the TiCrN composite-coated steel does not exhibit any red rust formation in the scribed areas, whereas uncoated steel exhibits red rust formation. The adhesion of the paint film is good on the coated steel, and it is removed in less than $5 \%$ of the area, when tested by an adhesive tape, whereas for uncoated steel the extent of removal of paint film is 40-50\%. The corrosion current densities of the composite coating in $3.5 \% \mathrm{NaCl}$ solution at room temperature were found to be much lower than that of uncoated steel substrate. Based on the electrochemical potentiodynamic polarisation results, TiCrN composite coating offers better corrosion resistance than uncoated steel.

Acknowledgments The authors would like to thank Oerlikon Coating Service Chennai for providing the different PVD coatings. The authors would like to thank Dr. Jeppiaar, Chairman, Dr. N. Marie Wilson, Director and Dr. V. Kannan, Principal of Jeppiaar Institute of Technology, for their constant encouragement in all endeavours. The authors are thankful to the reviewers for providing their useful comments, suggestions and guidelines during the course of revision to improve the technical quality of the present paper.

\section{References}

1. Batista JCA, Spain E, Housden J, Fuentes GG, Rebole R, Rodriguez $\mathrm{R}$ et al (2005) Characterisation of pristine and recoated electron beam evaporation plasma-assisted physical vapour deposition $\mathrm{Cr}-\mathrm{N}$ coatings on AISI M2 steel and WC-Co substrates. Thin Solid Films 491:177-183

2. Jehn AJ, Baumgartner ME (1992) Corrosion studies with hard coating-substrate systems. Surf Coat Technol 54-55:108

3. Fedrizzi L, Rossi S, Cristel R, Bonora PL (2004) Corrosion and wear behaviour of HVOF cermet coatings used to replace hard chromium. Electr Chem Acta 49:2803-2814

4. Singh H, Puri D, Prakash S (2005) Studies of plasma spray coatings on a Fe-base superalloy, their structure and high 
temperature oxidation behaviour. Anti-Corros Method Mater 52-2:84-95

5. Ding XZ, Tan ALK, Zeng XT, Wang C, Yue T, Sun CQ (2008) Corrosion resistance of CrAlN and TiAlN coatings deposited by lateral rotating cathode arc. Thin Solid Films 516:5716-5720

6. Baumvol IJR (1994) New trends in hard coatings technology. Nucl Instrum Methods Phys Res B 85:230-235

7. Pinkas M, Pelleg J, Dariel MP (1999) Structural analysis of $\left(\mathrm{Ti}_{1-\mathrm{x}} \mathrm{Al}_{\mathrm{x}}\right) \mathrm{N}$ graded coatings deposited by reactive magnetron sputtering. Thin Solid Films 355:380-384

8. Suzuki T, Huang D, Ikuhara Y (1998) Microstructures and grain boundaries of (Ti, Al) N films. Surf Coat Technol 107:41-47

9. Zhou M, Makino Y, Nose M, Nogi K (1999) Phase transition and properties of Ti-Al-N thin films prepared by rf-plasma assisted magnetron sputtering. Thin Solid Films 339(1):203-208

10. Bouzakis KD, Vidakis N, Michailidis N, Leyendecker T, Erkens G, Fuss G (1999) Quantification of properties modification and cutting performance of $\left(\mathrm{Ti}_{1-\mathrm{x}} \mathrm{Al}_{\mathrm{x}}\right) \mathrm{N}$ coatings at elevated temperatures. Surf Coat Technol 120:34-43

11. von Richthofen A, Cremer R, Witthaut M, Domnick R, Neuschütz D (1998) Composition, binding states, structure, and morphology of the corrosion layer of an oxidized Ti0.46Al0.54N film. Thin Solid Films 312(1):190-194

12. Cunha L, Andritschky M, Rebouta L, Silva R (1998) Corrosion of $\mathrm{TiN}$, (TiAl) $\mathrm{N}$ and $\mathrm{CrN}$ hard coatings produced by magnetron sputtering. Thin Solid Films 317(1):351-355

13. Jimenez C, Sanchez-Fernandez C, Morant C, Martinez-Duart JM, Fernandez M, Sanchez-Olias J (1999) Dependence of the mechanical and structural properties of $(\mathrm{Ti}, \mathrm{Al}) \mathrm{N}$ films on the nitrogen content. J Mater Res 14(7):2830-2837

14. ASTM D (2002) 3359-02: standard test methods for measuring adhesion by tape test. ASTM International, West Conshohocken, PA 